\title{
New semi-spherical radiofrequency energy device for liver resection: an experimental study in pigs
}

Petr Vávra ${ }^{1,2,3,12}$, Martina Škrobánková ${ }^{2}$, Jan Grepl ${ }^{4}$, Michal Crha ${ }^{5}$, Marek Penhaker ${ }^{3}$, Jana Jurčíková ${ }^{2}$, Miša Škorič ${ }^{7}$, Petr Raušer ${ }^{8}$, Petr Ostruszka ${ }^{1}$, Peter Ihnát ${ }^{1,2}$, Patricie Delongováa, ${ }^{10}$, Jana Dvořáčková9,10, Václav Procházka ${ }^{6}$, Dana Šalounová ${ }^{11}$, Nagy Habib ${ }^{12}$, Pavel Zonča ${ }^{1,2}$

\author{
${ }^{1}$ University Hospital Ostrava, Department of Surgery, Ostrava, Czech Republic \\ ${ }^{2}$ University of Ostrava, Faculty of Medicine, Department of Surgery, Ostrava, Czech Republic \\ ${ }^{3}$ Technical University of Ostrava, Faculty of Electrical Engineering and Computer Science, Department of \\ Cybernetics and Biomedical Engineering, ${ }^{4} \mathrm{Faculty}$ of Mechanical Engineering, Ostrava, Czech Republic \\ ${ }^{5}$ University of Veterinary and Pharmaceutical Sciences Brno, CEITEC VFU, Brno, Czech Republic \\ ${ }^{6}$ University Hospital Ostrava, Department of Vice-President for Science and Research, Ostrava, Czech Republic \\ ${ }^{7}$ University of Veterinary and Pharmaceutical Sciences Brno, Faculty of Veterinary Medicine, Department of \\ Pathological Morphology and Parasitology, ${ }^{8}$ Department of Surgery and Orthopaedics, \\ Small Animal Clinic, Czech Republic \\ ${ }^{9}$ University Hospital Ostrava, Institute of Pathology, Ostrava, Czech Republic \\ ${ }^{10}$ University of Ostrava, Faculty of Medicine, Institute of Pathology, Ostrava, Czech Republic \\ ${ }^{11}$ Technical University of Ostrava, Faculty of Economics, Department of Mathematical Methods in Economy, \\ Ostrava, Czech Republic \\ ${ }^{12}$ Hammersmith Hospital, Imperial College London, Liver and Pancreas Surgery, London, United Kingdom
}

Received March 16, 2014

Accepted November 10, 2015

\begin{abstract}
The aim of this experimental study was to verify a new semi-spherical surgical tool for bipolar radiofrequency liver ablation, which can solve some of the disadvantages of the commonly used device, such as long duration of ablation. A total of 12 pigs which were randomly divided into two groups were used. Each pig underwent resection of the two liver lobes. In group 1 , pigs were treated with the commonly used device; in group 2 the newly developed semispherical device was used. During surgery and the post-surgical period, many categories were observed and later analyzed. The blood count and biochemistry were monitored on days 0 , 14 and 30 from the operation. On day 14 since the liver resection, pigs underwent diagnostic laparoscopy to evaluate their condition focusing on the site of the liver lobe resection. On day 30 after operation, all pigs were euthanized and subjected to histopathological examination. Histopathological evaluation of thermal changes at the resection margin showed strong thermal alteration in both groups. Data between both groups were compared using median test for continuous variables and Fisher's exact test for categorical variables. Statistical analyses were performed with IBM SPSS software version 18.0. Statistical analysis of collected data did not prove any significant $(P<0.05)$ differences between the commonly used device and the newly designed surgical tool.
\end{abstract}

Animal study, pig model, liver ablation, radiofrequency energy

The liver is very frequently affected with metastases of colorectal carcinoma (Jemal et al. 2008). The incidence of colorectal carcinoma is increasing all around the world, including the Czech Republic (Ferlay et al. 2010; Pavlík et al. 2012). Therefore, it is necessary to focus research on the demands for instrumental equipment in liver surgery and the need to develop innovative designs (Vavra et al. 2014). This in vivo study follows an ex vivo study, which was done during the years 2009-2011. The pig as an animal model was chosen because of its availability, economic considerations, and relatively undemanding farming conditions (Varadarajulu et al. 2009; Lesser et al. 2011). Another medically justifiable

Address for correspondence:

Ass. Prof. Petr Vávra, M.D., Ph.D.

Department of Surgery, University Hospital in Ostrava

17. listopadu 1790 , Ostrava 70852

Czech Republic

Phone: +420 737550050

E-mail: petrvavra@yahoo.co.uk

http://actavet.vfu.cz/ 
reason for the selection of this species was that the pig liver is similar in physiological functions, size and topographic links to other abdominal organs of the human body. Several studies have been performed using an ex vivo and/or in vivo animal model to verify the effectiveness of radiofrequency on various tissue types (Johnson and Cadeddu 2003; Date et al. 2005).

The primary hypothesis was to demonstrate the feasibility and safety of the newly developed semi-spherical bipolar device for liver ablation and resection (RONJA) compared with the commonly used device for liver resection. The secondary hypothesis was to confirm that the system configuration of electrode needles into a semi-spherical shape was designed in such a way that it would shorten the ablation and thus the operation time while maintaining the same effect of thermal coagulation (Vavra et al. 2014).

\section{Materials and Methods}

This experimental in vivo study (no. 65/2012) was approved by the Institutional Animal Care and Use Committee of the University of Veterinary and Pharmaceutical Sciences Brno in accordance with Article 18, paragraph $6 \mathrm{~b}$, of Act No. 246/1992 on the protection of animals against cruelty. Our experiment was also approved by the Ministry of Education, Youth and Sports of the Czech Republic and was granted permission to be carried out on September 7, 2012. One-year-old pigs were provided by the Research Institute of Animal Production (Uhrineves, Department of Pig Breeding, Kostelec, address: Komenskeho 1240, 517 41, Czech Republic, accreditation number 444/2011MZE-17214, valid until April 6, 2016). The whole experiment took place in the research surgical theatre of the Faculty of Veterinary Medicine, University of Veterinary and Pharmaceutical Sciences Brno, Czech Republic.

Twelve pigs (Sus scrofa domestica) were randomly divided into two groups of six pigs. Pigs in group A underwent liver resection using the newly tested device and in control group B pigs were operated on with the commonly used surgical multiple needles device for radiofrequency liver ablation.

The surgical procedure

All animals were intramuscularly premedicated with a mixture of TKX - tiletamin-zolazepam (Zoletil, Virbac, France), ketamine (Narketan, Vetoquinol, Czech Republic), xylazine (Rometar, Bioveta, Czech Republic) (2 mg/kg from each subs.) and atropine (Atropin, Leciva, Czech Republic) $(0.02 \mathrm{mg} / \mathrm{kg})$. Anaesthesia was induced by intravenous propofol (Norofol, Norbrook Lab. Ltd., North Ireland) $(0.5-1 \mathrm{mg} / \mathrm{kg})$, then anaesthesia was maintained by a constant rate infusion of propofol $(0.1 \mathrm{mg} / \mathrm{kg} / \mathrm{min})$.

The surgical field and surroundings were shaved and made antiseptic by washing with iodopovidon (Betadine soap, Egis Pharmaceutical, Hungary); chlorhexidine (Nolvasan, Cymedica s.r.o., Czech Republic) was applied to the surgical field. During the surgical procedure Hartmann solution (B. Braun, Germany) $10 \mathrm{ml} / \mathrm{kg} / \mathrm{h}$ were administered to the animals intravenously through a cannulated auricular vein. Postoperatively, the animals were administered amoxicillin (15 $\mathrm{mg} / \mathrm{kg})$ and meloxicam $(0.4 \mathrm{mg} / \mathrm{kg})$ (Metacam, Boehringer Ingelheim, Germany) intramuscularly.

An upper middle laparotomy was performed with the position of the animal on its back. Two liver resections were always performed on each pig (Plate VI, Fig. 1) - one from the right lateral lobe and one resection of the left lateral lobe of the liver (Plate VI, Fig. 2). The resected samples were fixed in $10 \%$ formalin solution for a follow-up histopathological examination. The entire abdominal laparotomy was closed in three layers (peritoneum together with fascia, subcutaneous tissue, skin). A special antiseptic spray - Silver Aluminium Aerosol (Henry Schein, Inc., Germany) - bandage protection against contamination was applied to the surgical wound (Vavra et al. 2014).

Second phase

This part of the testing was focused on determining the status of healing as well as on postoperative complications. Aesculap (B. Braun Medical., s.r.o., Czech Republic) laparoscopy instrumentation was used for diagnostic intervention - a humane version of the endoscopic video unit Tele Pack X and laparoscopic optic Hopkins with an outer diameter of $5 \mathrm{~mm}$ and a length of $290 \mathrm{~mm}$ (Karl Storz Endoscopy, Germany) insufflation device Smith \& Nephew and laparoscopic set Harmonic ACE (Ethicon Endo-Surgery, LLC and Johnson \& Johnson company, USA).

Third phase

On the $30^{\text {th }}$ day after the first surgical liver resection, 12 porcine autopsies were performed, according to the protocol and lege artis.

Data between the standard device group and the RONJA group were compared using median test for continuous variables and Fisher's exact test for categorical variables. Statistical analyses were performed with IBM SPSS software version 18.0 


\section{Results}

Examination of blood samples showed no significant differences. The ablation time was shorter with the tested device RONJA (2.84 min in the left lobe and $1.17 \mathrm{~min}$ in the right lobe) compared to the commonly used device. In the newly designed instrument, there was also a shorter surgical time $(11.5 \mathrm{~min})$ in comparison with the commonly used device. Blood loss during the liver resections was less than $20 \mathrm{ml}$. In experimental group A the weight gain was on average $5.83 \mathrm{~kg}$ and in control group B it was $6.62 \mathrm{~kg}$. During the whole experiment several complications occurred. The spleen was deserosated in a pig in experimental group A.

Control laparoscopy showed postoperative adhesions in all 12 animals. As we expected, many adhesions were found in the abdominal cavity between the resected part of the liver and the omentum or the abdominal wall, respectively. Only one adverse event appeared during the inspection laparoscopy (Table 1). The transverse colon of one pig in experimental group A was injured when capnoperitoneum was being established. Death of one pig in control group B occurred in the postoperative period after the laparoscopic procedure. The cause of death was determined as animal circulatory failure due to respiratory insufficiency in the postoperative period in connection with Mycoplasma spp. infections.

Table 1. Data comparing the incidence of complications in liver resection with the newly designed device and the commonly used device.

\begin{tabular}{lccc}
\hline Type of complication & Standard device; n (\%) & RONJA; n (\%) & $P$ value \\
\hline & & & $1(16.7)$ \\
Complications during surgery & $0(0)$ & $0(0)$ & 1 \\
Post-operative complications & $1(16.7)$ & $4(66.7)$ & 0.061 \\
Complications during laparoscopy & $0(0)$ & $2(100)$ & - \\
Post-operative adhesions (liver) & $6(100)$ & $2(33.3)$ & 1 \\
Post-operative adhesions (spleen) & $2(33.3)$ & $1(16.7)$ & 1 \\
Pathological findings - ascites & $1(16.7)$ & $2(33.3)$ & 1 \\
Pathological findings - abscess & $0(0)$ & & 0.567 \\
Pathological findings in lungs & $4(66.7)$ & & \\
\hline
\end{tabular}

Veterinary pathologist described the nutritional status of the animals as 'good to very good'. Only one pig which had been injured in the transverse colon in the second phase, had an abscess in the subcutaneous space which had not caved into the abdominal cavity. Resection margins in the liver lobes were mostly covered with fibrous tissue at the adhesions. A small amount of serous effusion was observed in the abdominal cavity of four female pigs. The lungs of five pigs had pathological findings consisting of atelectatic bearings - acute inflammatory or chronic bronchopneumonia. Fibrinoid purulent pericardial effusion was observed in one of these pigs, no adhesions or effusions were observed in the thoracic cavity of the other four pigs.

Histopathological evaluation in haematoxylin-eosin of thermal changes at the resection margin showed strong thermal alteration in both groups. The depth of the thermal alteration was on average $4 \mathrm{~mm}$ larger in the cases of the newly tested instrument, dispersion of values was $12-17 \mathrm{~mm}$.

\section{Statistical analysis}

A two-sided value of $P<0.05$ was considered significant for all analyses. The statistical analysis definitely showed that there were no differences between experimental group A and control group B. 


\section{Discussion}

Radiofrequency energy has been used in medicine for more than a hundred years. First, French physicist D'Arsonval described the effects of alternating current at a frequency of $250 \mathrm{kHz}$ on biological tissue in Paris (D'Arsonval 1891). The first percutaneous radiofrequency ablation (RFA) of liver tumours in humans was published in 1993 (McGahan et al. 1993). Nowadays, radiofrequency ablation is a promising, gradually developing method. There are many studies which use radiofrequency in different ways to improve the protocol of liver lesions treatment (Vavra et al. 2009; Zacharoulis et al. 2009). The application of RF current between the electrodes leads to organ parenchyma and vessel coagulation. Radiofrequency resection significantly reduces blood loss and the need for blood transfusions in the postoperative period (Habib 2001; Ihnat et al. 2013). Many authors have used the porcine model in feasibility and safety studies of radiofrequency ablation of livers, lung, and pancreatic tissue (Solazzo et al. 2007; Crha et al. 2011).

This experimental study confirms the primary hypothesis and demonstrates the feasibility and safety of the newly developed semi-spherical bipolar device for liver ablation and resection. We have confirmed the secondary hypothesis, that the new semi-spherical bipolar radiofrequency device RONJA has advantages compared to the commonly used device such as faster ablation of the liver lobe and faster operation time while maintaining the same effect of ablation. The ablation and surgical time were shorter with the new device RONJA compared to the commonly used device, but due to the small number of pigs in our experimental group, it was not confirmed by statistical analysis (Vavra et al. 2014).

During our in vivo testing on the porcine model, no severe complications occurred which could be linked with the use of our newly developed instrument.

This experimental study in pigs has shown promising results for the utilization of the newly developed radiofrequency device for semi-spherical liver resection, however, further studies have to be performed before wider use of this device in clinical practice. In our experience, pigs appear as an effective experimental model for liver surgical procedures.

\section{Conflict of interest}

The authors declare no conflicts of interest.

\section{Acknowledgements}

This work was supported by MH CZ-DRO-FNOs/2012, MH CZ-DRO-FNOs/2013 and MH CZ-DROFNOs/2015, SGS VSB-TUO Grant No. SP2013/116 and by the project "CEITEC - Central European Institute of Technology" (CZ.1.05/1.1.00/02.0068) from the European Regional Development Fund. This study was also supported by the Long-term Development Plan of the Faculty of Medicine, University of Ostrava.

The work and the contributions were supported by the project SP2013/35 "Biomedical engineering systems IX" and TACR TA01010632 "SCADA system for control and measurement of process in real time". The paper was elaborated in the framework of the IT4 Innovations Centre of Excellence Project, reg. no. CZ.1.05/1.1.00/02.0070 supported by the Operational Programme 'Research and Development for Innovations' funded by the Structural Funds of the European Union and the state budget of the Czech Republic.

\section{References}

Crha M, Hlavsa J, Procházka V, Andrašina T, Svobodová I, Urbanová L, Pavlík T, Raušer P, Lorenzová J, Kala Z, Nečas A 2011: Radiofrequency ablation of pancreas and optimal cooling of peripancreatic tissue in an ex-vivo porcine model. Acta Vet Brno 80: 407-413

D’Arsonval MA 1891: Physiological action of alternating currents (in French). C R Soc Biol 43: 283-286

Date RS, McMahon RF, Siriwardena AK 2005: Radiofrequency ablation of the pancreas. I: Definition of optimal thermal kinitic parameters and the effect of simulated portal venous circulation in an ex-vivo porcine model. J Pancreas (Online) 6: 581-587

Ferlay J, Shin HR, Bray F, Forman D, Mathers C, Parkin DM 2010: Estimates of worldwide burden of cancer in 2008: GLOBOCAN 2008. Int J Cancer 127: 2893-2917 
Habib NA 2001: Liver cancer: Multitreatment modalities. Hepatogastroenterology 48: 2

Ihnat P, Vavra P, Rudinska L, Ostruszka P, Dostalik J 2013: Radiofrequency-assisted liver resection: short-term results in a single institution. Bratisl Lek Listy 114: 19-22

Jemal A, Siegel R, Ward E, Hao Y, Xu J, Murray T, Thun MJ 2008: Cancer statistics 2008. Ca-Cancer J Clin 58: 71-96

Johnson DB, Cadeddu JA 2003: Radiofrequency interstitial tumor ablation: dry electrode. J Endourol 17: 557-562

Lesser TG, Ritter F, Schlosser H, Boltze C, Hackenbroich C 2011: Effects of radiofrequency ablation on normal lung tissue in a swine model. Acad Radiol 18: 1318-1323

McGahan JP, Schieder P, Brock JM, Tesluk H 1993: Treatment of liver tumors by percutaneous radiofrequency electrocautery. Semin Intervent Radiol 10: 143-149

Pavlík T, Májek O, Mužík J, Koptíková J, Slavíček L, Fínek J, Feltl D, Vyzula R, Dušek L 2012: Estimating the number of colorectal cancer patients treated with anti-tumour therapy in 2015: the analysis of the Czech National Cancer Registry. BMC Public Health 10: 12-117

Solazzo SA, Ahmed M, Liu Z, Hines-Peralta AU, Goldberg SN 2007. High-power generator for radiofrequency ablation: larger electrodes and pulsing algorithms in bovine ex vivo and porcine in vivo settings. Radiology 242: $743-750$

Varadarajulu S, Jhala NC, Drelichman ER 2009: EUS-guided radiofrequency ablation with a prototype electrode array system in an animal model (with video). Gastrointest Endosc 70: $372-376$

Vavra P, Dostalik J, Zacharoulis D, Khorsandi SE, Khan SA, Habib NA 2009: Initial clinical results of a new bipolar radiofrequency ablation device. Conference: International Surgical Congress of the Association-ofSurgeons-in Great-Britain-and-Ireland Location: Bournemouth 52: 355-358

Vavra P, Penhaker M, Jurcikova J, Skrobankova M, Crha M, Ostruszka P, Ihnat P, Grepl J, Delongova P, Dvorackova J, Prochazka V, Salounova D, Skoric M, Rauser P, Habib N, Zonca P 2014: Semi-spherical radiofrequency bipolar device - a new technique for liver resection: experimental in vivo study on the porcine model. Technol Cancer Res Treat tcrt.2012.500432, first published on November 26, doi:10.7785/tcrt.2012.500432

Zacharoulis D, Khorsandi SE, Vavra P, Dostalik J, Navarra G, Nicholls JP, Jiao LR, Habib NA 2009: Pilot study for a new bipolar radiofrequency ablation/aspirator device in the management of primary and secondary liver cancers. Liver Int 29: 824-830 
Plate VI

Vávra P. et al.: New semi-spherical....... pp. 397-401

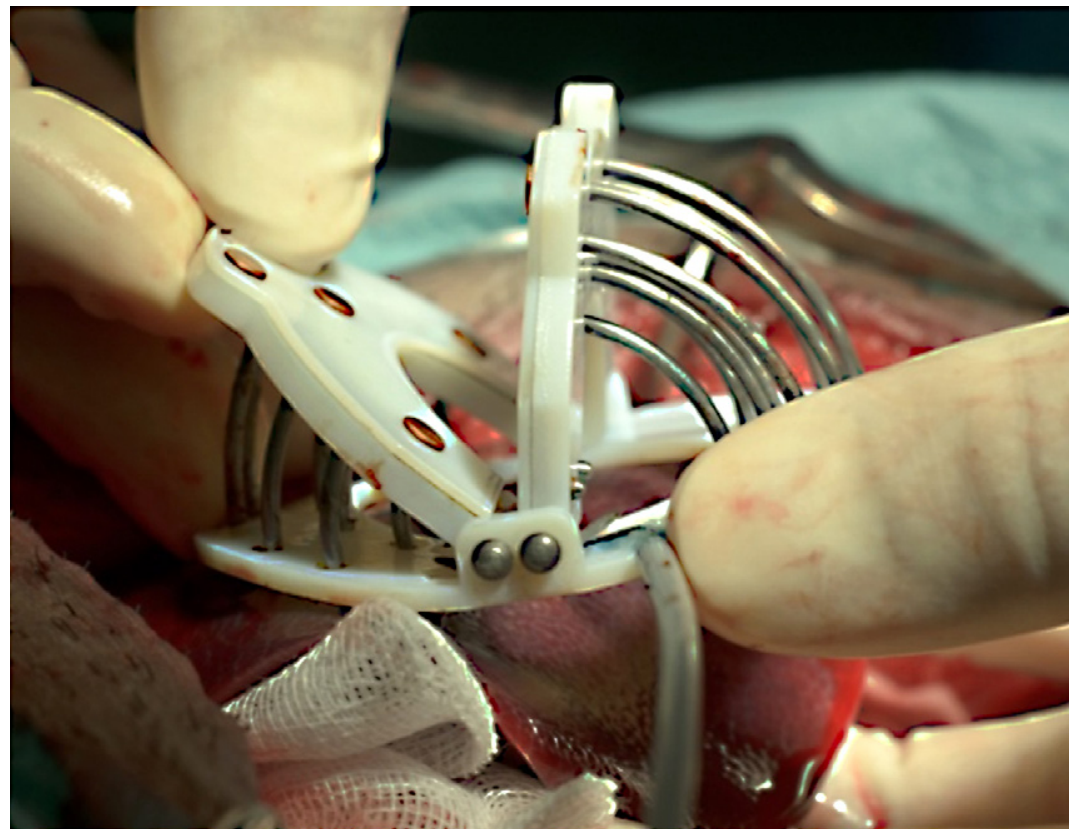

Fig. 1. In vivo study - example of practical application on pig's liver

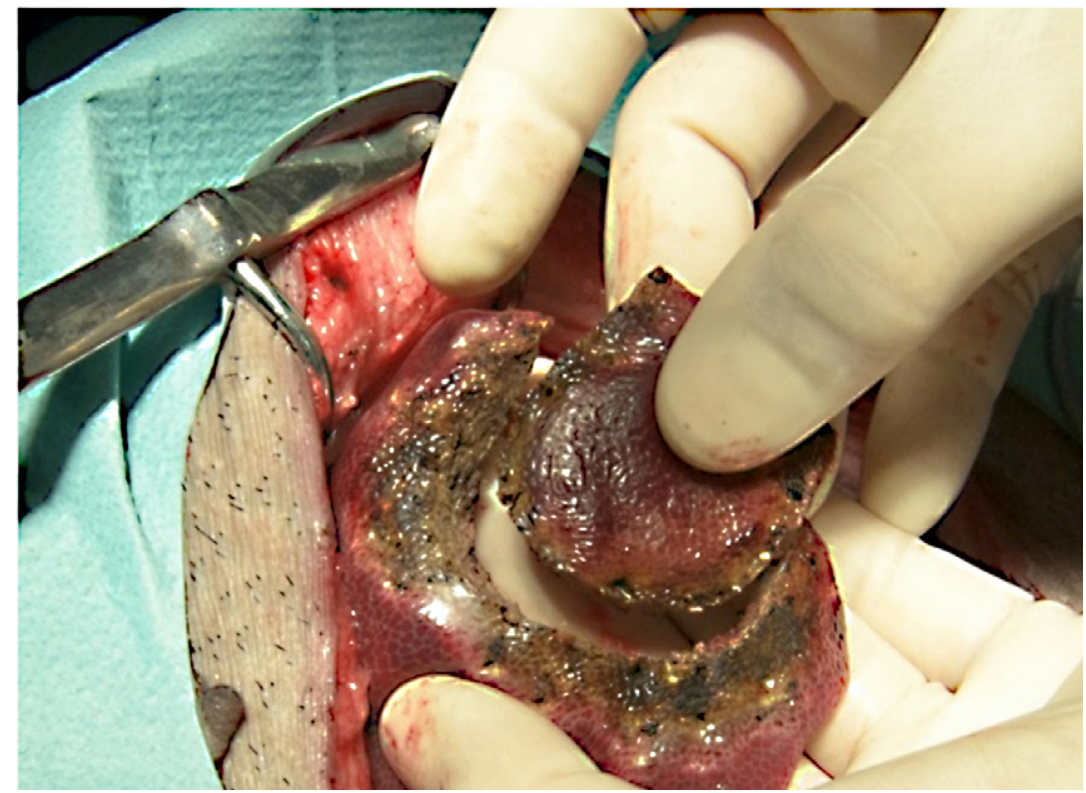

Fig. 2. View of the liver tissue after coagulation and surgical excision 